\title{
Analysis of Compartment Fires with Overhead Forced Ventilation
}

\section{CRAIG BEYLER}

Hughes Associates, Inc.

2730 University Blvd. West

Wheaton, Maryland 20902, USA

\begin{abstract}
Compartment fire data with either no ventilation or forced overhead ventilation are successfully modeled as well-stirred fire environments rather than two-layer fire environments. The extinction of flames is predicted using the limiting oxygen index concept linked with a well-stirred model of the fire environment. While the fire environment in compartments with overhead ventilation is quite different than naturally-ventilated fires or fires ventilated from floor level, a temperature model previously developed by Beyler and Deal is shown to predict preflashover temperatures in forced ventilation fires.
\end{abstract}

KEYWORDS: compartment fires, temperature, extinction, forced ventilation

\section{INTRODUCTION}

Most compartment fire experiments are conducted in rooms with an open door or window [1]. This type of test has been used as the foundation for nowclassical two-zone fire models [2]. Relatively few forced ventilation compartment fire experiments have been performed. Of the forced ventilation compartment fire experiments, the earlier work focused on forced ventilation provided at the base of the compartment $[3,4]$. Only relatively recently have overhead forced ventilation compartment fires been studied experimentally $[5,6]$. Because HVAC systems which provide room air via ceiling-mounted diffusers are very common in modern buildings, it is important that this scenario be understood.

In this investigation, the results of experiments in rooms with no ventilation (closed, but not sealed) and overhead ventilation will be analyzed to develop a theoretical framework for modeling such fires. This paper will focus on the temperatures achieved and the unique extinction mechanisms observed in these fires. Before delving into the analysis, the available experimental database and the phenomenology observed in these experiments will first be reviewed. 


\section{EXPERIMENTAL DATA}

As a part of a long-term project [3-6] in forced ventilation compartment fires, Foote [5] performed a series of fire tests in a closed compartment with no ventilation as well as a series in a forced ventilation compartment where the ventilation was provided either at the base of the compartment or at the top of the compartment (Figure 1). Exhaust was provided by a duct near the top of the compartment. Exhaust flows were monitored with a sharp-edge orifice meter in the exhaust duct. All these experiments were conducted in a test compartment $4 \mathrm{~m}$ by $6 \mathrm{~m}$ by $4.5 \mathrm{~m}$ high. In most of the tests the upper onethird of the compartment was made into a plenum with a $0.4 \mathrm{~m} \times 0.4 \mathrm{~m}$ opening connecting the compartment and plenum. The fire was provided by a methane pool-type burner in the center of the room. The height of the burner was varied from $0.23 \mathrm{~m}$ to $2.06 \mathrm{~m}$ above the floor. Ventilation rates varied from 0 to $0.5 \mathrm{~kg} / \mathrm{s}$ and heat release rates varied from 50 to $400 \mathrm{~kW}$. Only constant heat release rate fires were investigated. In experiments conducted with no ventilation, there was sufficient leakage area to prevent any pressure increase.

In their analysis of these tests Backovsky, Foote, and Alvares [6] observed that fires ventilated from below with more than 2-3 times the stoichiometrically required air flow appeared to yield well defined two layer fire environments as determined from vertical temperature profiles. Alternatively, they found that for fires ventilated from below with less than 2-3 times the stoichiometrically required air flow, the vertical temperature profiles increased linearly with height above the floor of the compartment, and as such, did not have good two layer qualities. This is in agreement with the observations of Orloff et al. [7] that for small ventilation openings, a well defined two layer environment is not achieved. Apparently, for the small fires Backovsky et al. [6] examined in a relatively large compartment, the secondary wall flows were sufficiently large compared to the primary air flow through the compartment to cause significant inter-layer mixing. Similarly, in tests with no ventilation, a welldefined two-layer environment was not achieved as indicated by the vertical temperature profile.

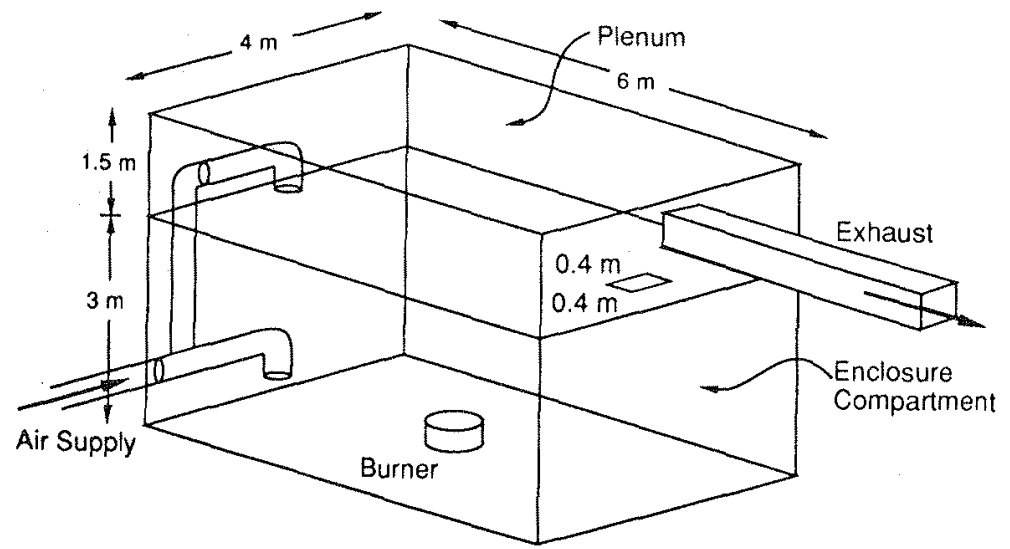

FIGURE 1. Schematic of the experimental compartment used by Foote [5]. The two alternate air supply locations and the plenum are shown. 
Backovsky et al. further observed that for fires ventilated from above, vertical temperature profiles were again linear with height. Hence, the environment was not a well-defined two-layer system, regardless of the ventilation rate. Presumably, this was due to the vertical mixing caused by the vertically downward air flow into the top of the enclosure. It was observed that all fires without ventilation ultimately extinguished themselves, and fires with insufficient overhead ventilation also self-extinguished. Foote observed that as extinction approached, the flame became blue in color and often detached from

the burner prior to extinction. Foote classified this behavior as 'ghosting.' No increase in the production (yield) of $\mathrm{CO}$ and unburnt fuel was observed as the flame approached extinction. This is consistent with the observation of Morehart [8] and indicates that the combustion efficiency is not reduced as extinction is approached.

In this investigation, enclosure fires with overhead ventilation are modeled with the goal of predicting the temperatures and the extinction behavior observed in Foote's experimental program.

\section{MODELING OF THE FIRE THERMAL ENVIRONMENT}

In a previous paper, Beyler and Deal [1] developed a simple model of both forced and naturally ventilated compartment fires which allowed the prediction of compartment temperatures. The model is based on a quasisteady simplified energy equation with a simple wall heat loss model. This model has been validated for both natural and forced ventilation fires. The model is outlined below.

The compartment temperature is given by the quasi-steady energy equation,

$$
\Delta \mathrm{T}=\frac{\dot{\mathrm{Q}}}{\dot{\mathrm{m}} \mathrm{c}_{\mathrm{p}}+\mathrm{h}_{\mathrm{k}} \mathrm{A}_{\mathrm{T}}}
$$

where $\dot{\mathrm{Q}}$ is the heat release rate, $\dot{\mathrm{m}}$ is the forced ventilation rate, $c_{\mathrm{p}}$ is the heat capacity of the gases, $A_{\mathrm{T}}$ is the internal surface area of the compartment, and $\mathrm{h}_{\mathrm{k}}$ is the heat loss coefficient for the compartment boundary given by

$$
h_{k}=0.4 \max \left(\sqrt{\frac{k \rho c}{t}}, \frac{k}{\delta}\right)
$$

The thermal properties of the boundary are the thermal conductivity, $k$, the density, $\rho$, the specific heat, $c$, and the boundary thickness, $\delta$, and $t$ is time. If there are multiple boundary types, the overall $h_{k} A_{T}$ is simply the sum over all of the boundaries.

Figure 2 shows a comparison of the predicted and measured temperatures in compartment fires with known ventilation rates taken from Reference 1. As the figure indicates, the method works quite well. The data shown in Figure 2 include naturally ventilated fires in which the exhaust rate 


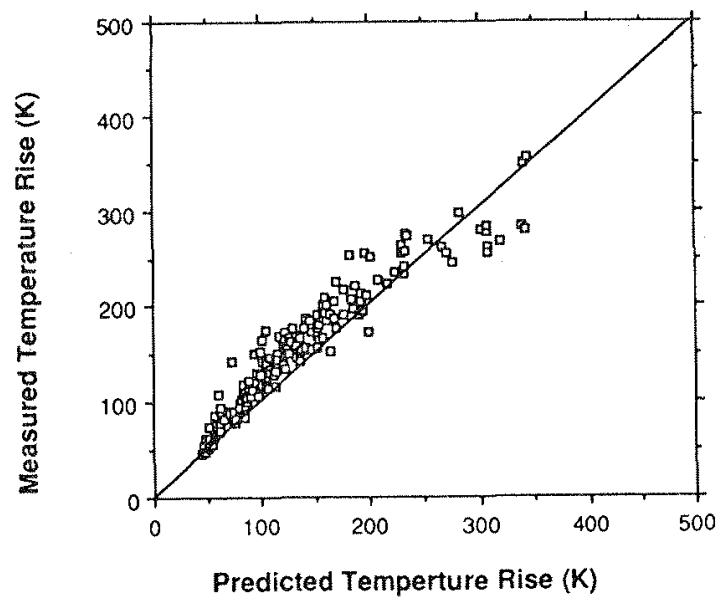

FIGURE 2. Comparison of predicted and measured temperatures using the Deal and Beyler model for compartment fires with known ventilation rates [1].

was measured and forced ventilation fires where ventilation was provided from the base of the compartment.

Figure 3 shows a comparison of the Foote data with the predictions of the Beyler and Deal model. The measured temperature rise is the average over the upper half of the enclosure. The figure shows that the method was quite successful in correlating the data. This figure shows only data taken up to 2000 seconds into the tests. At longer times the heat loss model breaks down. The breakdown in the heat loss model at long times is likely due to the very simple nature of the steady state heat loss model. All resistance to heat flow is assumed to be in the boundary itself. This is not viewed as a serious problem in practical applications, because few real fires remain in the growth stage for this duration.

The data shown in Figure 3 is for experiments of two types: forced ventilation from below (with and without a plenum) and forced ventilation from above. In the Foote experiments, ventilation from above was provided at ceiling level and ventilation from below was provided at floor level. As the figure shows, the Beyler and Deal model works equally well for fires ventilated from above as for fires ventilated from below.

For the closed compartment tests the quasi-steady method is clearly not appropriate since a steady state is impossible. A nonsteady energy balance for the "closed" compartment can be expressed as a simple differential equation.

$\mathrm{m} \mathrm{c}_{\mathrm{p}} \frac{\mathrm{dT}}{\mathrm{dt}}=\dot{\mathrm{Q}}-\mathrm{h}_{\mathrm{k}} A_{\mathrm{T}} \Delta \mathrm{T}$

where the mass of the fuel is ignored, the energy lost through leakage is ignored, and the initial temperature is equal to the ambient temperature. $\Delta \mathrm{T}$ is expressed as the temperature above this datum. For constant heat release rates this can be solved, yielding 


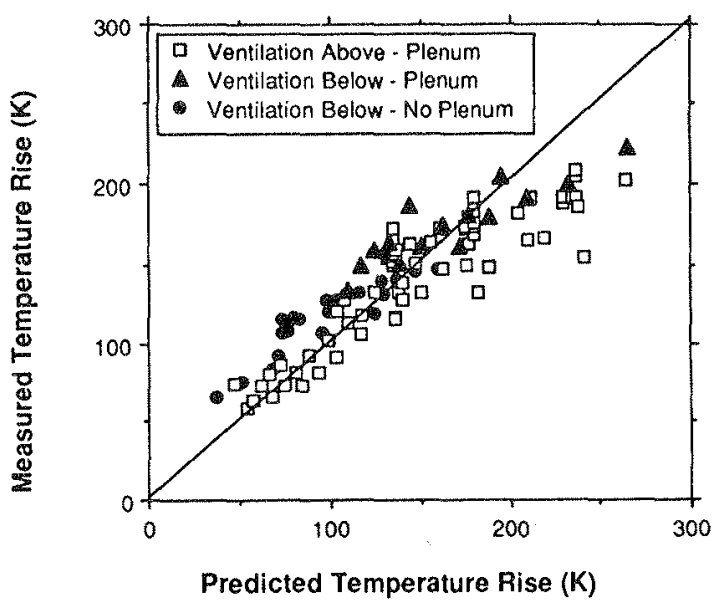

FIGURE 3. Comparison of measured and predicted temperature rise for the Foote data [5] with forced ventilation.

$\Delta \mathrm{T}=\frac{2 \mathrm{~K}_{2}}{\mathrm{~K}_{1}^{2}}\left(\mathrm{~K}_{1} \sqrt{\mathrm{t}}-1+\mathrm{e}^{-\mathrm{K}_{1} \sqrt{\mathrm{t}}}\right)$

where

$\mathrm{K}_{1}=\frac{2(0.4 \sqrt{\mathrm{k} \rho \mathrm{c}}) \mathrm{A}_{\mathrm{T}}}{\mathrm{m} \mathrm{c}_{\mathrm{p}}}$

$\mathrm{K}_{2}=\frac{\dot{\mathrm{Q}}}{\mathrm{m} \mathrm{c}_{\mathrm{p}}}$

Figure 4 shows a comparison of the measured average temperature rise throughout the compartment for the closed compartments with no ventilation [5] and the predicted temperature rise using Equation 4. The temperature rise is correlated well by the method, though there is a general tendency to underpredict the temperature rise.

The comparison of the Foote data with the predictions of the Deal and Beyler method shows that the quasi-steady Beyler and Deal method (Equation 1) can be used for forced overhead ventilated fires directly. In fires in completely closed, unventilated compartments, Equation 4 can be used to provide estimates of the compartment temperatures.

\section{MODELING FLAME EXTINCTION}

It remains to predict if and when flame extinction will occur for the closed compartments and for the compartments ventilated from above. The compartment fires with no ventilation supplied will first be addressed. These 


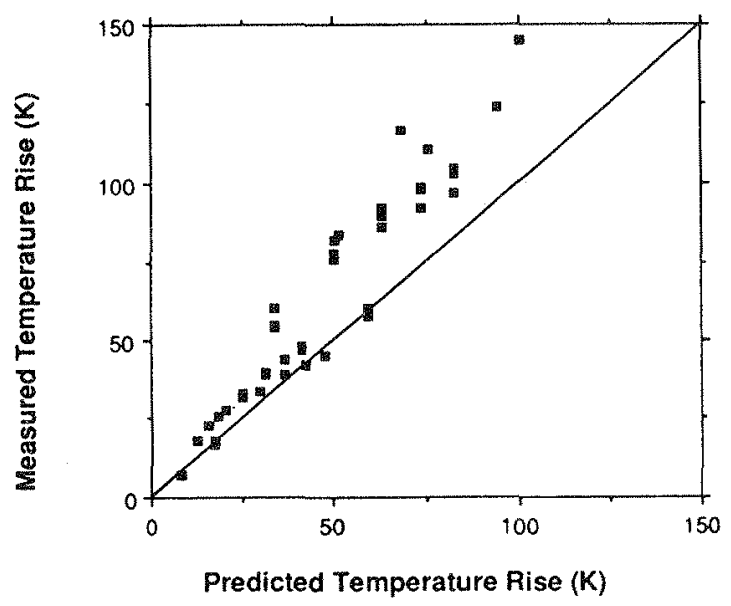

FIGURE 4. Comparison of measured average temperature rise and the predicted temperature rise (Equation 4) for the closed compartment Foote data [5].

tests did, of course, extinguish due to a lack of oxygen. The compartment may be considered well-stirred by the plume flow and the fire will extinguish when the compartment reaches the limiting oxygen index (LOI). This well-stirred compartment model gives a particularly simple result. If the compartment is considered a closed system, it is simply necessary to determine the amount of combustion which will consume enough oxygen to reduce the concentration to the LOI. This gives the following expression for the extinction condition.

$$
\frac{Y_{\mathrm{O}_{2}, \infty}-Y_{\mathrm{O}_{2}, \mathrm{LOI}}}{Y_{\mathrm{O}_{2, \infty}}}\left[\Delta \mathrm{H}_{\mathrm{R}, \mathrm{O}_{2}} \mathrm{Y}_{\mathrm{O}_{2, \infty}} \rho_{\infty} \mathrm{V}\right]=\int_{0}^{\mathrm{t}_{\mathrm{ext}}} \dot{\mathrm{Q}} \mathrm{dt}
$$

The left hand side is the energy release required to reduce the oxygen concentration to the LOI and the right hand side is the corresponding output from the fire. Equation 5 ignores leakage from the "closed" compartment. The Foote compartment, like all conventional compartments, leaked sufficiently to avoid any pressure rise. For a constant heat release rate fire Equation 5 yields

$$
t_{\text {ext }}=\left(Y_{\mathrm{O}_{2, \infty}}-Y_{\mathrm{O}_{2}, \mathrm{LOI}}\right)\left[\frac{\Delta \mathrm{H}_{\mathrm{R}, \mathrm{O}_{2}} \rho_{\infty} \mathrm{V}}{\dot{\mathrm{Q}}}\right]
$$

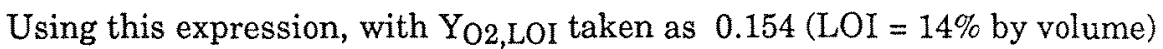
as measured for methane by Simmons and Wolfhard [9], yields the results shown in Figure 5. Experiments by Morehart [8] were conducted using air diluted with products of combustion rather than nitrogen as used by Simmons and Wolfhard. The resulting methane LOIs were $12.4 \%$ by volume for a $50 \mathrm{~cm}$ burner and $14.3 \%$ by volume for a $9 \mathrm{~cm}$ burner. This supports the $14 \%$ value used here. While the LOI is expected to be reduced by increasing temperature [10], the effect of temperatures observed in the Foote tests reduces the LOI by less than $1.5 \%$ by volume and, as such, temperature corrections have not 


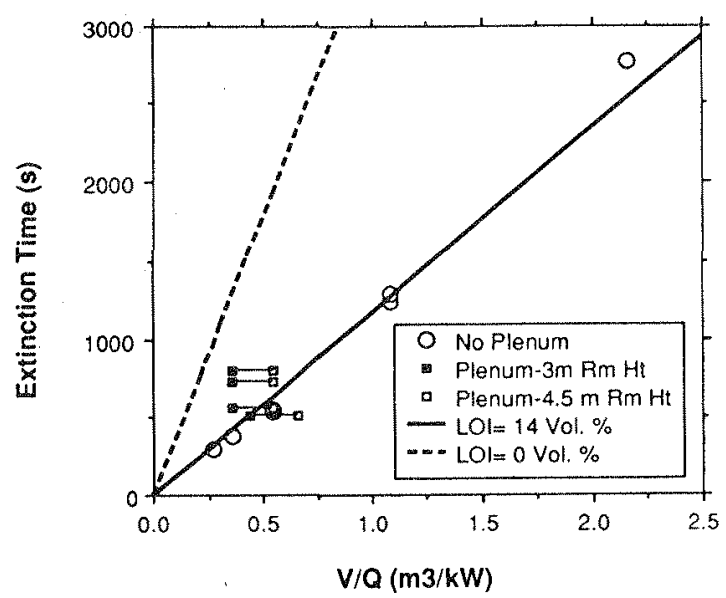

FIGURE 5. Comparison of extinction time theory with closed compartment Foote data [5]. The room height not including the plenum is $3 \mathrm{~m}$ and the room height including the plenum is $4.5 \mathrm{~m}$.

been made. The figure shows that the model works very well for the tests without a plenum installed. Since there is a $0.4 \times 0.4 \mathrm{~m}$ hole connecting the room and plenum volumes in the tests with a plenum, it is unclear if the plenum volume should be included in the room volume. The figure shows the results of assuming both that the room volume does and does not include the plenum volume. In general, the model works well. The curve labeled

$\mathrm{LOI}=0 \%$ corresponds to using all available oxygen in the room. Clearly, this is not achieved in any of the tests.

For compartments ventilated from above, the well-stirred compartment model can again be used. It is useful to first examine the steady-state oxygen concentration which is expected from a steady fire. If the steady-state oxygen concentration is less than the LOI, then the fire is expected to be extinguished. The steady state oxygen concentration is simply

$\mathrm{Y}_{\mathrm{O}_{2}, \mathrm{SS}}=\mathrm{Y}_{\mathrm{O}_{2, \infty}}-\left[\frac{\dot{\mathrm{Q}}}{\dot{\mathrm{m}} \mathrm{Y}_{\mathrm{O}_{2, \infty}} \Delta \mathrm{H}_{\mathrm{R}, \mathrm{O}_{2}}}\right]$

Using the Simmons and Wolfhard LOI as the steady state oxygen concentration yields the line labeled theory in Figure 6. The theory indicates that all data points above the line should extinguish. This is in excellent agreement with the Foote experimental results. The theoretical line corresponds to an equivalence ratio of 0.325 . The "no extinction" data point which lies slightly above the line was a fire elevated $2.06 \mathrm{~m}$ above the floor.

\section{Flame Extinction Time}

Given this success in predicting whether extinction occurs, it remains to predict the time to extinction. Extinction delays result from the use of oxygen which was originally in the compartment as in the closed compartment case. 


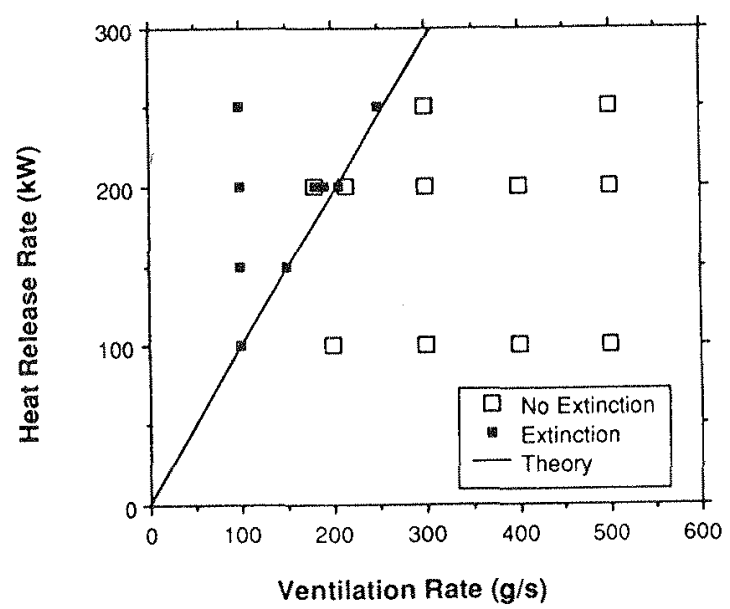

FIGURE 6. Comparison of theory (Equation 6) and experimental extinction data of Foote [5]. The theory indicates that all data points above the line should extinguish.

The time to extinction can be modeled by predicting the time required for the well-stirred compartment oxygen concentration to reach the LOI. The differential equation describing the oxygen concentration in the compartment is

$\frac{\mathrm{d} \mathrm{Y}_{\mathrm{O}_{2}}}{\mathrm{dt}}=\frac{\dot{m}}{\mathrm{~m}}\left(\mathrm{Y}_{\mathrm{O}_{2}, \infty}-\mathrm{Y}_{\mathrm{O}_{2}}\right)-\left[\frac{\dot{\mathrm{Q}}}{\rho_{\infty} \mathrm{V} \Delta \mathrm{H}_{\mathrm{R}, \mathrm{O}_{2}}}\right]$

For a steady ventilation rate and burning rate as found in the Foote tests, this yields

$$
t_{\text {ext }}=\frac{\rho_{\infty} V}{\dot{m}} \ln \left[\frac{Y_{\mathrm{O}_{2}, \infty}-Y_{\mathrm{O}_{2}, \mathrm{SS}}}{\mathrm{Y}_{\mathrm{O}_{2}, \mathrm{LOI}}-\mathrm{Y}_{\mathrm{O}_{2}, \mathrm{SS}}}\right]
$$

Figure 7 shows a comparison of the measured and predicted extinction times for experiments ventilated from above that did in fact self-extinguish. The agreement is generally quite good. The experiments which are less well predicted are those that had steady state oxygen concentrations near the LOI, i.e., those tests with long extinction times. Under these conditions, the solution is very sensitive to variations in LOI and the steady state oxygen concentration. The solid data points are experiments with elevated fire sources (1.14 $\mathrm{m}$ above the floor). Apparently, fires can persist longer if the source is elevated. While this phenomenon is not understood, it does imply deviation from the well-stirred compartment model in this situation.

\section{DISCUSSION}

The general problem of defining the conditions under which a fire compartment is best modeled as a well-stirred or two-layer system remains to be solved. Any solution to this problem must consider the momentum of the 


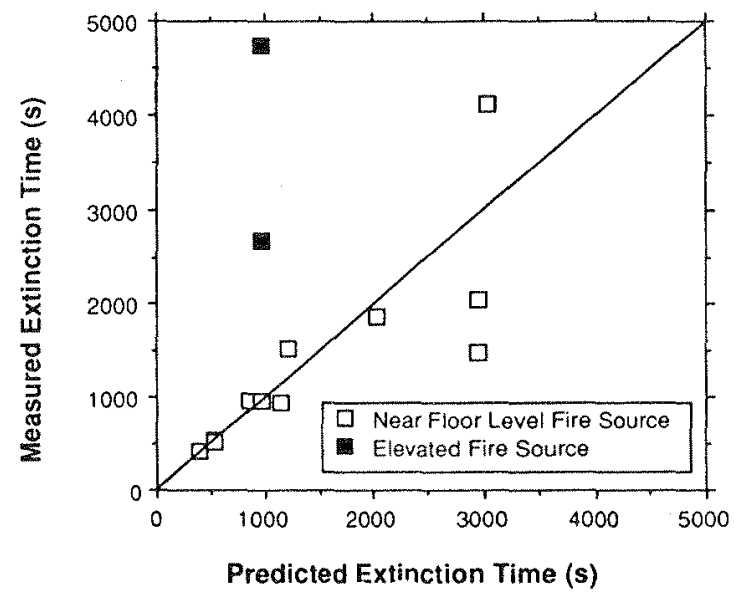

FIGURE 7. Comparison of measured and predicted extinction time for the Foote data [5] ventilated from above.

ventilation, the total ventilation rate, the heat release rate, the wall flows, and vent mixing. This is clearly beyond the scope of the present work and will require specialized compartment fire experiments.

The present predictions of flame extinction work well for methane fires. It remains to be seen if extinction is actually observed for fuel sources for which volatilization rate is a function of the fire environment. Rather than extinguish the flame, the fuel volatilization rate may be reduced such that the flame is preserved at or near the extinction condition, yielding a limit-type flame. In practical terms this would mean that in compartments with overhead air supply, the heat release rate may be reduced to reach an oxygen concentration just larger than the limiting oxygen index. Further experimental work is required in this area.

It is important to note that the extinction modeling indicates that the compartments are well approximated by a well-stirred compartment, while the temperature profiles for these same experiments indicate a situation somewhere between a two-layer and a well-stirred system [6]. This apparent contradiction can arise because heat is lost through the wall surfaces, but no mass transfer occurs. As such, a compartment which is well-stirred from a gas species standpoint may not exhibit a uniform temperature over the height of the compartment. This points out the need for vertical species profiles, not available from the Foote experiments.

Morehart [8] has made both temperature and species concentration profiles in his hood experiments. He found that while the species concentrations were very uniform over the height of the hood, the temperature profile varied linearly with height. While these hood tests are quite different from the Foote tests analyzed here, the Morehart results are illustrative of how species and temperature profiles can be dissimilar. 


\section{CONCLUSIONS}

This work demonstrates that the temperatures achieved in closed compartments and compartments with overhead ventilation can be predicted using the simple Beyler and Deal model. This is an important extension of the conditions under which this model can be used. Previously, validation of this model was only available for scenarios where combustion air was provided via a vent in the lower portion of the compartment. Also, the extinction of flames in closed or overhead ventilated compartment fires are well predicted using a well-stirred compartment fire model and the limiting oxygen index concept.

In addition, this analysis of closed and overhead ventilated fire experiments points out the need to develop criteria to establish whether a twolayer or a well-stirred compartment will best describe a given fire condition. The extinction model, validated in this work, is an important component required to solve the problem of window breakage in closed compartments.

\section{REFERENCES}

1. Deal, S., and Beyler, C.L., "Correlating Temperatures in Preflashover Room Fires," J. of Fire Prot. Engr., 2(2), pp. 33-48, 1990.

2. Quintiere, J., "Fundamentals of Enclosure Fire 'Zone' Models," J. of Fire Prot. Engr., 1(3), pp. 99-119, 1989.

3. Alvares, N., Foote, K.L., and Pagni, P., "Forced Ventilated Enclosure Fires," Combustion Science and Technology, 39, pp. 55-81, 1984.

4. Foote, K.L., Pagni, P.J., and Alvares, N.J., "Temperature Correlations for Forced-Ventilated Compartment Fires," First International Symposium on Fire Safety Science, Hemisphere Publ. Co., pp. 139-148, 1986.

5. Foote, K.L., "1986 LLNL Enclosure Fire Test Data Report," UCID-21236, Lawrence Livermore National Laboratory, 1987.

6. Backovsky, J., Foote, K.L., and Alvares, N.J., "Temperature Profiles in Forced-Ventilation Enclosure Fires," Second International Symposium on Fire Safety Science, Hemisphere Publ. Co., pp. 315-324, 1989.

7. Orloff, L., Modak, A.T., and Markstein, G.H., "Radiation from Smoke Layers," Seventeenth Symposium (International) on Combustion, The Combustion Institute, pp. 1029-1038, 1979.

8. Morehart, J., Zukoski, E., and Kubota, T., Species Produced in Fires Burning in Two-layered and Homogeneous Vitiated Environments, California Institute of Technology, 1990.

9. Simmons, R.F., and Wolfhard, H.G., "Some Limiting Oxygen Concentrations for Diffusion Flames in Air Diluted with Nitrogen," Combustion and Flame, 1, pp.155-161, 1952.

10. Beyler, C., "Flammability Limits of Premixed and Diffusion Flames," Chapter 1-17, SFPE Handbook of Fire Protection Engineering , DiNenno (Ed.), NFPA, Quincy MA, 1988. 